\title{
REPRESENTAÇÕES EM DISCURSOS DE PARANINFOS SOBRE A PROFISSÃO DE PROFESSOR NOS CURSOS DE CIÊNCIAS CONTÁBEIS E FISIOTERAPIA
}

\author{
Elisane Scapin Cargnin ${ }^{1}$ \\ Gessélda Somavilla Farencena ${ }^{2}$ \\ Cristiane Fuzer ${ }^{3}$
}

\begin{abstract}
Resumo: Este trabalho tem o propósito de analisar a linguagem usada para manifestar representações sobre o professor e a sua profissão em discursos de paraninfos para solenidades de formatura. Foram usados pressupostos teóricos da Gramática SistêmicoFuncional de Halliday \& Matthiessen (2004) para análise das escolhas léxico-gramaticais em articulação com as formas de representação dos atores sociais no nível sociossemântico propostas por van Leeuwen (1997). Constataram-se diferentes representações sobre a profissão de professor em dois contextos específicos. No discurso da paraninfa do curso de Fisioterapia, o professor, na função de agente em orações materiais, mentais e relacionais, é representado principalmente com a missão de entusiasmar os alunos para o ofício da fisioterapia e aconselhá-los a amarem a profissão. No discurso do paraninfo das Ciências Contábeis, o professor, na função de agente em orações relacionais e mentais, é representado como detentor e transmissor de conhecimento e como amigo e conselheiro dos alunos.
\end{abstract}

Palavras-chave: Gramática Sistêmico-Funcional; discurso de formatura; representações; professor.

\begin{abstract}
This paper aims to analyze the language used to demonstrate representations about professor as well as his or her profession in commencement speaker's speeches for graduation ceremonies. Theoretical assumptions from the Systemic Functional Grammar by Halliday \& Matthiessen (2004) were used in order to analyze the lexicogrammatical choices in articulation with the representation ways for social actors in the sociosemantic level proposed by van Leeuwen $(1997,2008)$. Different representations for the profession of a professor were found in two specific contexts. In the commencement speaker's speech from the Physical Therapy Major, as the agent in material, mental and relational clauses, the professor is represented mainly with the mission of motivating students for the Physical Therapy profession. In the commencement speaker's speech from the Accounting Major, as the agent in mental and relational clauses, the professor is represented as the holder and carrier of knowledge and as the students' friend as well as mentor.
\end{abstract}

Key-words: Systemic Functional Grammar; graduation speech; representations; professor.

\footnotetext{
${ }_{1}^{1}$ Professora de Língua Portuguesa e Redação no Colégio Estadual Professora Edna May Cardoso em Santa Maria. elisanesc1@hotmail.com.

2 Tutora do Curso de Letras EaD/UAB da Universidade Federal de Santa Maria (UFSM). É doutoranda também em Estudos Linguísticos na mesma universidade e integrante do Núcleo de Estudos em Língua Portuguesa (NELP/UFSM).gesseldaf@yahoo.com.br.

${ }^{3}$ Professora Adjunta no Departamento de Letras Vernáculas e do Programa de Pós-Graduação em Letras da Universidade Federal de Santa Maria (UFSM). É pós-doutoranda do Programa de Estudos Pós-Graduados em Linguística Aplicada e Estudos da Linguagem (LAEL) na Pontifícia Universidade Católica de São Paulo (PUCSP). crisfuzer@yahoo.com.br.
} 


\section{Introdução}

$O$ estudo da linguagem em diferentes contextos tem sido o foco de diversas pesquisas que partem da concepção de linguagem como prática social (FUZER, CABRAL e OLIONI, 2011; MELO e NUNES, 2011; GOMES, 2011; FUZER, 2010; MEURER, 2004, dentre outros). No que se refere especificamente ao contexto acadêmico, vários estudos têm contribuído para a compreensão dos textos representativos das atividades acadêmicas, explicitando estruturas retóricas e características linguísticas dos gêneros textuais utilizados nesse contexto, como resenhas, resumos, projetos de pesquisa, artigos acadêmicos, comunicações, pôsteres (PENHA, 2011; BARBARA e MACEDO, 2011; MOTTA-ROTH e HENDGES, 2010; VIVAN, 2010; MOTTA-ROTH, 2009; GIERING, 2009, dentre outros).

Um evento acadêmico ainda pouco explorado em pesquisas linguísticas é a solenidade de formatura, o ato simbólico de conclusão de curso de graduação e o último compromisso acadêmico oficial dos estudantes. Em trabalho anterior, NOME constataram que, no contexto solene de formatura, os discursos, em geral produzidos previamente como textos escritos para serem lidos em público, trazem representações de sentimentos, ações, comportamentos e, principalmente, da profissão para a qual os estudantes foram formados. Um desses discursos é o trazido pelo paraninfo, que, por meio da linguagem, representa experiências como docente e mantém uma relação social de maior ou menor distanciamento com os formandos e com os demais participantes da solenidade.

Neste trabalho, buscamos evidenciar representações para a profissão de professor manifestadas nos discursos produzidos por paraninfos de dois cursos de graduação - Ciências Contábeis e Fisioterapia. Tendo em vista que a atividade docente vem passando por um processo de desvalorização por parte da sociedade, das políticas governamentais e, principalmente, dos jovens que acabam se esquivando dos cursos de licenciatura, a relevância deste estudo está centrada na busca de se compreender como os próprios professores e, de modo especial, como profissionais que não são professores por formação, mas que escolheram seguir o caminho da docência universitária, representam a profissão docente em seus discursos.

A resposta para essa questão está fundamentada na análise de escolhas léxico-gramaticais, especificamente as que realizam a metafunção ideacional experiencial da linguagem da Gramática Sistêmico-Funcional (HALLIDAY e MATTHIESSEN, 2004), em articulação com formas de representação de atores sociais (VAN LEEUWEN, 1997, 2008).

\section{Pressupostos teóricos}

A perspectiva sistêmico-funcional da linguagem tem por base pressupostos da Gramática Sistêmico-Funcional (GSF) desenvolvida por Halliday $(1985,1994)$ e 
Halliday e Matthiessen (2004). Parte da ideia de que a linguagem é um sistema sociossemiótico, uma representação simbólica que organiza as possibilidades de significação no contexto social. O funcionamento da linguagem escrita ou oral é descrito na Gramática Sistêmico-Funcional, segundo Halliday e Matthiessen (2004), sob critérios semânticos e sintáticos, porque identifica a relação entre diferentes elementos linguísticos em qualquer tipo de texto e sua função na construção de significados.

A teoria hallidayana preocupa-se em investigar as escolhas léxico-gramaticais feitas em um determinado contexto e os diversos significados que podem ser produzidos por essas escolhas nos textos. Para Halliday (1989), texto é a linguagem que está em funcionamento, ou seja, "qualquer instância da vida em que a linguagem esteja agindo em um contexto de situação" 4 (p. 10).

O contexto, de acordo com Halliday e Matthiessen (2004), relaciona-se com a organização da linguagem (que desempenha funções). Hasan (1989) propõe que os elementos que compõem a estrutura de um texto sejam definidos pelo trabalho que realizam em uma configuração contextual específica.

Esta, segundo a autora, é a soma das características significativas de uma atividade social e diz respeito ao contexto de situação e suas três variáveis que, de acordo com Halliday (1989), são campo (aquilo que está acontecendo, a natureza da ação social que está sendo realizada); relações (quem participa da ação, a natureza, os estatutos e os papéis dos participantes e as relações entre eles: maior ou menor formalidade, proximidade, etc.) e modo (a organização simbólica do texto, o canal, a forma estrutural como o texto é apresentado, o papel desempenhado pela linguagem). Um texto é, nessa perspectiva, resultado da experiência da linguagem humana em diferentes contextos sociais.

Com as três variáveis contextuais relacionam-se três metafunções desempenhadas pela linguagem, as quais, por sua vez, são realizadas por diferentes sistemas léxico-gramaticais. A metafunção ideacional experiencial, relacionada à variável contextual campo, é realizada pelo sistema de transitividade; a interpessoal, ligada à variável contextual relações, é realizada pelo sistema de MODO; e a textual organiza os significados ideacionais e interpessoais por meio da estrutura TemaRema, realizando a variável modo (HALLIDAY e MATTHIESSEN, 2004).

Neste trabalho, dentre as categorias de análise mencionadas, são utilizadas as categorias léxico-gramaticais que realizam a metafunção ideacional experiencial, que diz respeito às formas como as experiências e ações estão representadas por meio da linguagem nos discursos de formatura.

O sistema de transitividade, de acordo com Halliday e Matthiessen (2004), é dado pela oração, que se constitui de três componentes: processo, participante e circunstância. O processo se realiza por grupos verbais; os participantes, que podem ser pessoas ou coisas, seres animados ou inanimados, por grupos nominais ou

\footnotetext{
${ }^{4}$ As traduções estão sob a responsabilidade das autoras deste artigo.
} 
pronominais; as circunstâncias, por advérbios e grupos preposicionais cuja finalidade é adicionar informações aos processos em que os participantes estão envolvidos. Os significados experienciais são realizados por escolhas que se fazem no sistema de transitividade.

Para Halliday e Matthiessen (2004, p.181), a "transitividade é um sistema da oração que afeta não apenas a forma verbal que serve como processo, mas também os demais componentes, os participantes e as circunstâncias". Os processos se realizam por grupos verbais; os participantes, por grupos nominais; as circunstâncias, por grupos adverbais e preposicionais, com a finalidade de adicionar informações aos processos em que os participantes estão envolvidos. Esses componentes são categorias semânticas que mostram como fenômenos da nossa experiência do mundo (acontecimentos, fatos ou mensagens) são representados por meio da linguagem.

$\mathrm{Na}$ GSF, os processos dividem-se em três grandes grupos: materiais, mentais e relacionais. Há ainda processos que se situam da fronteira entre os três anteriores: os processos comportamentais, verbais e existenciais. A análise dos componentes das orações de um texto - processos, participantes e circunstâncias - possibilita evidenciar como determinadas escolhas léxico-gramaticais representam experiências dos indivíduos no mundo.

De acordo com Halliday e Matthiessen (2004), nas orações materiais, há dois participantes principais, que são o Ator e a Meta. O Ator é quem realiza a ação e sua presença é obrigatória; a Meta é o participante que é afetado de algum modo pelo processo.

As orações mentais representam experiências que não são do mundo físico, mas do mundo da consciência (HALLIDAY e MATTHIESSEN, 2004). Nessas orações, os participantes são o Experienciador e o Fenômeno. Processos mentais podem projetar outras orações, que se denominarão Macrofenômeno e Metafenômeno.

As orações relacionais, tipicamente realizadas por processos de "ser", representam características e identidades (HALLIDAY e MATTHIESSEN, 2004). Em orações relacionais em que caracterizam entidades, os participantes são Portador e Atributo. Em orações em que se representam identidades, os participantes são Identificado e Identificador.

No que diz respeito às orações comportamentais, os processos comportamentais são ações que englobam comportamentos físicos e psicológicos realizados de forma simultânea. Por isso, estão localizados na fronteira entre os processos mentais e materiais, segundo Halliday e Mathiessen (2004). Nessas orações, os participantes são o Comportante e, eventualmente, o Comportamento.

Nas orações verbais, o processo de "dizer" cobre qualquer tipo de troca simbólica de significado (HALLIDAY e MATTHIESSEN, 2004). Nesse tipo de oração, os participantes são o Dizente (aquele que diz), a Verbiagem (aquilo que está sendo 
dito), o Receptor (para quem se dirige a mensagem), o Alvo (aquele que se quer atingir com o processo de dizer). Assim como os processos mentais, os verbais podem projetar outras orações: no lugar da Verbiagem, pode haver um Relato ou uma Citação.

Quanto às orações existenciais, Halliday e Mathiessen (2004) defendem que os processos existenciais representam algo que existe ou acontece. $\mathrm{Na}$ língua portuguesa, são tipicamente realizados pelos verbos haver e existir. O participante da oração existencial é o Existente.

Opcionalmente, as orações podem apresentar circunstâncias, que são tipicamente realizadas por grupos adverbiais ou preposicionais. Sua função é adicionar ao processo informações relacionadas a localização de tempo e espaço, causa, modo, dentre outras.

Os componentes léxico-gramaticais podem ser associados a categorias sociossemânticas que evidenciam formas de representação dos atores sociais envolvidos nos discursos (FUZER, 2008), por meio das quais os enunciadores incluem ou excluem atores sociais "para servir aos seus interesses e propósitos em relação aos leitores a que se dirigem" (VAN LEEUWEN, 1997, p. 180). As categorias mais gerais de exclusão e inclusão são subdividas em outras mais específicas.

Por meio da exclusão, atores sociais são suprimidos ou encobertos no discurso. A supressão ocorre quando o ator social não é mostrado ao longo da mensagem. $O$ encobrimento ocorre no momento em que o participante, embora presente, não está explícito no texto. Nesse caso, a exclusão é amenizada, isto é, o ator social não é totalmente excluído, pois pode não ser mencionado em relação à determinada atividade, mas é mencionado em outras partes do texto, podendo ser recuperado. Segundo van Leeuwen (2008), é possível excluir atores sociais com a utilização de alguns recursos linguísticos, como: nominalização, adjetivação, elipse, apagamento do agente em estrutura passiva ou do participante Beneficiário.

A inclusão pode ocorrer, dentre outras formas, por Ativação, Passivação, Impersonalização ou Generalização. Na Ativação, segundo van Leuwen (1997), o ator social é representado como agente. Léxico-gramaticalmente, a agência pode se realizar por meio da função de Ator em orações materiais Experienciador em orações mentais, Dizente em orações verbais, Atribuidor em orações relacionais, Comportante em orações comportamentais. Na Passivação, o ator social é representado como afetado ou beneficiado pelo processo, o que pode se realizar pelas funções de Meta, Beneficiário, Fenômeno, Alvo, Receptor e Portador.

Assim, no nível léxico-gramatical em associação com o sociossemântico, as representações são construídas e manifestadas nos textos. Consoante a isso, neste trabalho, busca-se verificar como as representações para a profissão de professor são construídas e manifestadas por meio dos recursos linguísticos de transitividade e das categorias de Ativação e Passivação em dois discursos de formatura proferidos por paraninfos. 


\section{Metodologia}

Para coletar os dados necessários ao estudo do funcionamento da linguagem na construção de representações do ator social professor e sua profissão nos discursos de formatura, inicialmente, entrou-se em contato com uma instituição de ensino superior em Santa Maria, que forneceu os e-mails de professores que atuaram como paraninfos em solenidades de formatura. Em um segundo momento, foram solicitados aos professores indicados pela instituição os textos que produziram para proferir seus discursos nas solenidades de formatura de que participaram como paraninfos. Para este trabalho, foram selecionados os discursos do paraninfo de uma turma do curso de Fisioterapia e outro do curso de Ciências Contábeis, tendo como critério de seleção o mesmo período em que foram proferidos: janeiro de 2010.

Para análise dos textos, foram adotados os seguintes passos:

a) seleção das orações que apresentam os itens lexicais "professor" e "profissão" e elementos que os referenciem, como pronomes e grupos nominais do mesmo campo semântico;

b) descrição e análise das funções léxico-gramaticais desempenhadas pelos referentes "professor" e "profissão" no nível da oração;

c) identificação das formas de representação do ator social professor e sua profissão com base nas categorias de ativação e passivação.

Para preservar a identidade das pessoas citadas nos textos selecionados, quando mencionadas, as nomeações foram substituídas pela palavra NOME.

\section{Análise e discussão dos resultados}

Nesta seção, são analisadas escolhas léxico-gramaticais em associação com formas de representação do ator social professor e sua profissão nos discursos de formatura selecionados.

\subsection{Análise do discurso do paraninfo de Ciências Contábeis}

A análise de elementos léxico-gramaticais que constituem o discurso produzido pelo paraninfo do curso de Ciências Contábeis evidenciam três diferentes representações para o professor. Uma delas é a de transmissor de conhecimentos, como se verifica neste excerto em que o paraninfo (cuja formação é na área de Ciências Contábeis) se inclui no discurso como professor:

1- Certamente este convite, não foi apenas fruto dos ensinamentos que por ventura possa Ihes ter transmitido durante nosso breve convívio [...].

A função léxico-gramatical Beneficiário desempenhada pelo participante Ihes representa os afilhados como recebedores de uma atividade realizada pelo paraninfo. Este, por sua vez, desempenha a função de Dizente em relação ao 
processo verbal cognitivo ter transmitido. Essas escolhas léxico-gramaticais representam um profissional cuja ação principal é falar, enquanto os alunos são repositórios de ensinamentos.

Constata-se, assim, o discurso de uma concepção de ensino considerada tradicional, em que apenas o professor é agente. No discurso desse paraninfo, o professor ainda tem a representação da época em que a escola formava tarefeiros, pessoas preparadas para o trabalho, principalmente na indústria. Essa ideia de que o conhecimento é transmitido faz parte de uma pedagogia tradicional (SAVIANE, 1997), em que o aluno ouve o único detentor do conhecimento. Em outras palavras, o professor não é visto como um problematizador, que leva os alunos a pensarem e propõe discussões para que compartilhem e construam conhecimentos sobre sua área de formação. A função primordial do professor é, no texto em análise, transmitir conteúdos que provavelmente também lhe foram transmitidos.

Essa representação é reforçada em outra passagem do texto:

2- Durante a fase de formação profissional vocês tiveram a oportunidade de receber informações valiosas e adquirir os próprios conhecimentos.

Nesse excerto, o agente está encoberto (não é explicitado quem fornece as informações valiosas), ficando em segundo plano a responsabilidade da instituição e dos seus professores na formação dos contabilistas. É destacado o papel dos alunos que, na função léxico-gramatical de Beneficiário (recebedor de informações e cliente que se utiliza dos serviços prestados por alguém que detém conhecimentos), são representados, novamente, de forma passiva. É reiterada a representação do professor como "detentor do conhecimento" e do aluno como repositório de informações, que é contraposta a outra (ainda que mencionada com menor ênfase): a representação da relação professor-aluno como bilateral, como a troca de conhecimentos e amizade.

O professor como amigo e conselheiro dos alunos é outra representação encontrada no discurso em análise, como evidenciam as passagens destacadas no excerto a seguir:

3- [...] este convite, não foi apenas fruto dos ensinamentos que por ventura possa lhes ter transmitido durante nosso breve convívio, mas em muito, creio, pela amizade que aos poucos [professor e aluno] construímos, pelos momentos vividos no ambiente universitário, com trocas de ideias e informações, com algum conselho ou alguma orientação que a idade permite fazer. A vocês, minha admiração e amizade.

No nível léxico-gramatical, a Circunstância de causa (pela amizade que aos poucos construímos) evidencia que o paraninfo vivenciou uma relação de amizade com os formandos, e essa relação os levou a confiarem ao professor a tarefa de discursar na solenidade de formatura. A amizade também desempenha a função de Meta do processo construímos, de que participam professor e alunos. No nível sociossemântico, isso significa que, no âmbito das relações interpessoais, o professor não é o único agente. 
Enquanto no campo da técnica o professor é representado como o único agente (porque somente ele detém o conhecimento), no âmbito das relações sociais parece haver um espaço para os alunos participaram de forma ativa, como indica a Circunstância com trocas de ideias e informações. A ativação se dá pela escolha da palavra trocas, que implica necessariamente a participação de mais de um ator social (aluno-aluno, aluno-professor). Pode-se associar essa representação com a visão pedagógica de Paulo Freire, para quem o professor, na convivência amorosa com seus alunos, assume uma postura curiosa e aberta, ao mesmo tempo em que "provoca seus alunos a se assumirem enquanto sujeitos [...] do ato de conhecer" (FREIRE, 1999, p.11).

A terceira representação manifestada no discurso do paraninfo do curso de Ciências Contábeis é a da pessoa realizada profissionalmente. O segmento a seguir se constitui de elementos linguísticos que denotam tal representação.

4- Sou grato a NOME, por oportunizar a continuidade de minhas atividades como professor, profissão simplesmente gratificante, na qual me realizo plenamente.

Como Experienciador do processo mental me realizo, intensificado pela Circunstância de modo plenamente, o paraninfo se inclui no discurso com professor que se sente satisfeito profissionalmente - não como contabilista, mas como professor. O Atributo gratificante, intensificado pela Circunstância simplesmente, reforça a representação da profissão docente como responsável pela satisfação vivenciada pelo paraninfo. Essas expressões de sentimentos são utilizadas para representar a profissão de professor como um meio de realização e satisfação pessoal.

Assim, no discurso do paraninfo que desempenhou atividades docentes no curso de Ciências Contábeis, o professor é representado, no campo da técnica, como transmissor de informações e conhecimentos e, no campo das relações interpessoais, como amigo e conselheiro dos alunos. Mediante essas circunstâncias, a profissão de professor é representada como um meio de realização profissional.

\subsection{Análise do discurso da paraninfa de Fisioterapia}

A análise linguística do discurso da paraninfa do curso de Fisioterapia mostrou também três representações para o professor. Uma delas é a de profissional em formação, que se "faz" pelo convívio com seus alunos. No primeiro momento em que se dirige aos formandos, a paraninfa faz referência à sua trajetória como docente e à importância do convite da turma para ela. Em relação à sua trajetória docente, a paraninfa inclui-se no discurso como agente dos processos verbal e material destacados no excerto a seguir: 
5- Peço licença, para, nesse momento dirigir-me aos formandos, os quais tive o prazer de conduzi-los desde abril de 2008, quando iniciei o caminho da docência.

A oração verbal serve para marcar o direcionamento do conteúdo da fala a receptores específicos - os formandos. Estes passam a desempenhar, na oração seguinte, a função de Meta do processo conduzir, cujo Ator é a própria paraninfa. Mediante essas escolhas léxico-gramaticais, constrói-se a representação do professor como guia, numa analogia que aqui se faz com o pastor, que conduz as ovelhas para algum lugar. Mas o "pastor", nesse caso, não tinha experiência no ofício quando assumiu a tarefa. A representação da inexperiência é realizada léxicogramaticalmente pela oração material quando iniciei o caminho da docência. A escolha pelo processo iniciei retrata seu contexto de formação profissional: foi formada para atuar como fisioterapeuta e não como professora. Nessas circunstâncias, quem poderia participar de sua formação docente se não os próprios alunos?

Na sequência do seu discurso, a paraninfa reconstrói a sua experiência inicial como professora:

6- Lembram, eu como iniciante com receio do novo e vocês questionando acerca da nova professora. [...] Naquele momento não sabia exatamente o significado da docência em minha vida [...].

Os Atributos circunstanciais como iniciante e com receio do novo evidenciam a falta de experiência no exercício da docência. A falta de conhecimento do significado dessa profissão está explicitada na oração mental não sabia exatamente o significado da docência, de que a paraninfa participa como Experienciador. Nessa situação, a função de Circunstância de assunto acerca da nova professora pode ser interpretada literalmente: a professora era nova não só por estar trabalhando pela primeira vez naquela instituição com aquela turma, mas também por estar começando, naquele momento, seu processo de formação como professora.

Essa realidade representada no discurso da paraninfa vai de encontro à constituição de um papel social, que implica, de acordo com Richter e Moraes (2011, p. 524), "reconhecer que, antes de desempenhar os papéis, o sujeito deve conhecêlos".

Após dois anos (de 2008, quando iniciou a dar aulas para a turma, a 2010, quando ocorreu a solenidade de formatura) em sala de aula, a paraninfa elabora uma definição de professor:

7- [...] hoje entendo claramente que um professor é produto do aprendizado contínuo de que desfruta da convivência com os acadêmicos $[\ldots]$.

Como Experienciador do processo mental cognitivo entendo, modalizado pela Circunstância de modo claramente, a paraninfa demonstra sua conviç̧ão 
acerca do significado de professor, expresso por uma oração relacional: é produto do aprendizado contínuo de que desfruta da convivência com os acadêmicos. Mesmo encoberto pela nominalização do processo "aprender" (aprendizado), o professor é incluído como Experienciador junto a seus alunos. Por meio dessas funções léxico-gramaticais, é representado seu processo de formação docente: no início do trabalho na instituição, não conhecia o significado da docência, ao passo que, no momento da formatura dos seus alunos, representa-se como conhecedora da identidade do professor. Os alunos são, por conseguinte, os atores sociais responsáveis por sua formação. A partir disso, tem-se a representação do professor não como um profissional formado, mas que se constrói e aprende, na convivência com seus alunos, não apenas a prática, mas também, e principalmente, o sentido da profissão.

Essas escolhas linguísticas refletem o contexto profissional da paraninfa: sua "formação" pedagógica se deu na interação com os alunos, no convívio com eles, uma vez que, provavelmente, durante sua formação como fisioterapeuta, não teve preparação pedagógica. Isso justifica a definição de professor que ela apresenta como Fenômeno do seu entendimento (um professor é produto do aprendizado contínuo). Ela se vê em aprendizado contínuo, porque não havia aprendido a ser professora durante sua formação profissional. Talvez por isso ensinar ainda é, para ela, um mistério, presente no próximo segmento:

8- Esta homenagem me encoraja a perseverar no mistério do ensinar, e tenho certeza que consegui passar um pouco do meu entusiasmo e da minha realização profissional como fisioterapeuta para vocês [...].

Nesse excerto, verifica-se a segunda representação para o professor no discurso: a entusiasta. Essa representação se realiza por meio da oração consegui passar um pouco do meu entusiasmo para vocês (correspondendo a "entusiasmei vocês"), de que a fisioterapeuta-professora é, ao mesmo tempo, Dizente e Ator, já que "passou", provavelmente por meio de palavras e ações. A ideia de realização profissional também se manifesta nesse discurso, mas, diferentemente do que ocorre no discurso do paraninfo das Ciências Contábeis, o motivo da satisfação não é a docência, e sim a atividade fisioterapêutica.

9- [...] sabemos, que a finalidade de qualquer professor, em qualquer lugar do mundo, é preparar pessoas que algum dia terão tanto conhecimento quanto ele e este foi o meu papel. [...].

Por meio da Circunstância em qualquer lugar do mundo, que, de acordo com van Leuween (1997), configura-se como um recurso sociossemântico de generalização dos atores sociais, a paraninfa considera ser obrigatório ao professor preparar pessoas com conhecimento igual ao dele, haja vista a escolha pela oração relacional atributiva para caracterizar as pessoas beneficiadas pelo trabalho do professor: pessoas que terão tanto conhecimento quanto ele. Essa ideia está, de 
certa forma, ancorada ${ }^{5}$ na representação do professor como transmissor de conhecimentos, já que a correlação "tanto... quanto" estabelece um nível de igualdade no grau de conhecimentos, muito semelhante ao que ocorre no processo de transmissão, sem que sejam consideradas as diferentes experiências e identidades que constituem os indivíduos.

Portanto, no discurso da paraninfa da área de Fisioterapia, duas representações foram explicitadas: o professor se forma na convivência com seus alunos e é entusiasta na preparação para outras profissões. A terceira representação, mesmo que implicitamente, é semelhante à que se manifestou no discurso do paraninfo das Ciências Contábeis, a representação do professor como transmissor de conhecimentos, indicando, mais uma vez, a falta de uma formação pedagógica institucionalizada.

\section{Considerações finais}

A análise das escolhas linguísticas que constituem os discursos dos paraninfos dos cursos de Ciências Contábeis e de Fisioterapia possibilitou desvelar como o professor e sua profissão estão representados. Com base nos fundamentos teóricos da Gramática Sistêmico-Funcional de Halliday e Matthiessen (2004) e nas categorias sociossemânticas de van Leeuwen $(1997,2008)$, foram analisados os significados ideacionais produzidos por essas escolhas em termos de representações.

No discurso do paraninfo do curso de Ciências Contábeis, o professor aparece incluído por Ativação, desempenhando, principalmente, a função de Dizente. Dessa forma, é representado como detentor e transmissor de informações aos alunos no que se refere ao campo do conhecimento. No âmbito das relações interpessoais, entretanto, é representado como amigo e conselheiro dos alunos. A profissão docente é representada, por fim, como um meio de realização profissional.

As escolhas linguísticas no discurso da paraninfa à turma de Fisioterapia, por sua vez, representam o professor incluído por Ativação, desempenhado as funções de Experienciador no processo de aprender a ensinar, bem como de Dizente e Ator no processo de entusiasmar os alunos para o ofício da fisioterapia. Ancorada na representação do professor como transmissor de informações e conhecimentos, a identidade do professor se resume a preparar pessoas para que tenham o seu mesmo grau de conhecimento que o professor.

Essas representações, evidenciadas pelas análises léxico-gramaticais e sociossemânticas, refletem a complexidade do agir docente e a dificuldade de definilo. A realidade representada nos discursos reforça a ausência de institucionalização do papel de professor, razão pela qual seu trabalho é, de acordo com Richter e

\footnotetext{
${ }^{5}$ Ancoragem é uma categoria da teoria das Representações Sociais de Moscovici (2009). Trata-se de um processo que aproxima aquilo que é estranho, perturbador, que não pode ser comunicado, a alguma categoria já existente, familiar.
} 
Moraes (2011, p. 529), "muitas vezes delegado a pessoas sem a devida formação, deixando transparecer que as diretrizes de sua profissão são marcadas por expectativas cognitivas" e não normativas. Talvez por isso a profissão de professor seja "aberta" a profissionais das mais diversas áreas, como contabilistas e fisioterapeutas que, mesmo se formação pedagógica, atuam e são reconhecidos como professores, ao passo que professores, sem formação em Ciências Contábeis e Fisioterapia, muito provavelmente não seriam autorizados a atuar nessas profissões.

Agradecimentos: Agradecemos ao Conselho de Desenvolvimento de Pessoal de Nível Superior (CAPES) pelo apoio financeiro durante o desenvolvimento da pesquisa.

\section{Referências}

BARBARA, L.; MACEDO, C. M. M. de. Processos verbais em artigos acadêmicos: padrões de realização da mensagem. In: BARBARA, L.; MOYANO, E. Textos em linguagem acadêmica: explorações sistêmico-funcionais em espanhol e português. Campinas, SP: Mercado das Letras, 2011.

FUZER, C. Formas de representação de atores sociais no contexto jurídico penal. The ESPecialist, São Paulo, v. 31, n. 1, p. 21-47, 2010.

- Contexto e léxico-gramática em interação: análise de uma sentença condenatória. Revista Letras, Santa Maria, v. 20, n. 40, p. 113-132, jan./jun. 2010.

Linguagem e representação nos autos de um processo penal: como operadores do direito representam atores sociais em um sistema de gêneros. $270 \mathrm{fl}$. Tese (Doutorado em Letras), Universidade Federal de Santa Maria, Santa Maria, 2008.

; CABRAL, S. R. S.; OLIONI, R. C. A seleção brasileira de futebol a serviço da cerveja: análise multifuncional de texto na perspectiva da gramática sistêmicofuncional. Calidoscópio, São Leopolodo, v. 9, n. 3, p. 188-197, set./dez. 2011.

FREIRE, P. Pedagogia da Autonomia - Saberes necessários à prática educativa. São Paulo, Brasil: Paz e Terra, 1997.

GIERING, M. E. A organização retórica macroestrutural de artigos de divulgação científica midiática para adultos e para jovens: fatores influentes. In: SEMINÁRIO INTERNACIONAL DE LETRAS E LINGUÍSTICA, 1., Uberlândia, 2009. Anais... Uberlândia: $\quad 2009 . \quad$ Disponível em: <http://www.ileel.ufu.br/anaisdosilel/pt/arquivos/gt_lg03_artigo_7.pdf>. Acesso em: 11 fev. 2013. 
GOMES, M. C. A. Corpo, política e tecnologização: um estudo da representação de Dilma Rousseff no contexto da mídia. Cadernos de Linguagem e Sociedade, v. 12, n. 1, p. 11-29, 2011.

HALLIDAY, M. A. K.; HASAN, R. Language, context, and text: aspects of language in a social-semiotic perspective. Oxford: Oxford University Press, 1989.

HALLIDAY, M.A.K.; MATTHIESSEN, C. An introduction to functional grammar. $3^{\text {th }}$ ed. London: Arnold, 2004.

HASAN, R. The structure of a text. In: Halliday, M.A.K.; HASAN H. Language, context and text: aspects of a language in a social-semiotic perspective. Oxford: Oxford University Press, 1989.

MELO, S. H. D.; NUNES, J. G. O discurso da medicina e da reza na (re)construção de identidades. Cadernos de Linguagem e Sociedade, v. 12, n. 1, p. 104-127, 2011.

MEURER, J. L. Ampliando a noção de contexto na Lingüística Sistêmico-Funcional e na Análise Crítica do Discurso. Linguagem em (Dis)curso, Tubarão, v. 4, n.esp, p. 133-157, 2004.

MOSCOVICl, S. Representações sociais: investigações em psicologia social. Trad. Pedrinho A. Guareschi. 6. ed. Petrópolis, RJ: Vozes, 2009.

MOTTA-ROTH, D. Popularização da ciência como prática social e discursiva. Coleção Hipers@beres, v. 1, nov. 2009. Disponível em: <www.ufsm.br/hipersaberes>. Acesso em: 11 fev. 2013.

MOTTA-ROTH, D.; HENDGES, G. R. Produção textual na universidade. São Paulo: Parábola, 2010.

PENHA, D. T. S. Aspectos discursivos que constituem a autoria no gênero resenha acadêmica. In: CONGRESSO INTERNACIONAL DA ABRALIN, 7., Curitiba, fev. 2011. Anais... Curitiba: ABRALIN, 2011. p. 960-973. Disponível em: <http://www.abralin.org/abralin11_cdrom/artigos/Dalva_Teixeira.pdf>. Acesso em: 11 fev. 2013.

RICHTER, M. G.; AMARAL, J. Papel Social e Emancipação: Discutindo as Bases da Profissão Docente. SIGNUM: Estud. Ling., Londrina, n. 14/1, p. 523-550, jun. 2011.

SAVIANI, Demerval. Pedagogia Histórico-Crítica: primeiras aproximações. Campinas: Autores Associados, 1997.

VAN LEEUWEN, T. A representação dos actores sociais. In: PEDRO, E. R. (Org.). Análise Crítica do Discurso. Lisboa: Caminho, 1997.

Discourse and Practice: New Tools for Critical Discourse Analysis. New York: Oxford University Press, 2008. 
VIVAN, E.G.S. Principais usos de processos verbais e metáforas interpessoais em artigos de Linguística Aplicada. São Paulo: PUCSP, $208 \mathrm{fl}$. Tese (Doutorado em Linguística Aplicada e Estudos da Linguagem), Pontifícia Universidade Católica de São Paulo, São Paulo, 2010. 